\title{
Physical and chemical properties of rice grain of variety Rapan at different seeding rates and does of nitrogen fertilizers
}

\author{
Elina Papulova*, Svetlana Chizhikova, Knarik Olkhovaya, and Natalia Tumanyan \\ Federal Scientific Rice Centre, laboratory of rice quality, 350921, Krasnodar, Russia
}

\begin{abstract}
The paper presents the results of evaluating the rice variety Rapan grown in 2018, 2019 at different seeding rates and doses of nitrogen fertilizers, according to the main amylographic characteristics of starch dispersion and fracturing. In 2018 and 2019, when growing variety Rapan with seeding rates of 4, 6 and 8 million viable seeds, the highest values were noted for the "fracturing" trait at a nitrogen dose of $92 \mathrm{~kg} / \mathrm{ha}$ of active ingredient. In 2018, they amounted to 31,35 and $41 \%$, respectively, in 2019 - 13, 12 and 12\%, respectively. The following tendency in the change of rice quality traits was noted: in the samples grown without the use of nitrogen, low fracturing was revealed, while in the $\mathrm{N}_{92}$ variants the value of the trait was maximum, with $\mathrm{N}_{184}$ - the minimum. Indicators for the "maximum viscosity" at a nitrogen dose of $92 \mathrm{~kg} / \mathrm{ha}$ of active ingredient had the lowest values at all three seeding rates and amounted to 484, 500 and 485 Br.units in 2018, respectively. In 2019 - 471, 440 and $480 \mathrm{Br}$. units. The opposite pattern was observed when determining the viscosity indices: at the minimum values of fracturing, the viscosity indices were maximum and decreased at high values of this trait.
\end{abstract}

\section{Introduction}

Rice is a highly productive cereal crop and is consumed mainly as a whole grain after processing. Rice is unique in that it provides about $25 \%$ of the world's dietary calorie intake and $75 \%$ of the diet of the population in developing countries [1, 2]. Its processed products are high in calories and easily digestible [3, 4]. The consistency of the cooked rice is of paramount importance. Consumer preferences in terms of appearance, taste and texture are different: some prefer glutinous rice, others prefer crumbly. The consistency of rice (friability, stickiness) is mainly related to the content of amylose and amylopectin, and the aroma of cooked rice is due to the volatile compound 2-acetyl-1-pyrroline [5, 6]. Characteristics of rice grain quality for the consumer, as a rule, include the content of broken rice, the gelatinization temperature of the starch dispersion, the consistency of the glued starch [7, 8]. Evaluating the rice varieties according to these indicators, one can make recommendations on the use of milled rice for the preparation of a certain type of dish.

\footnotetext{
* Corresponding author: elya888.85@mail.ru
} 
Providing the population with high-quality rice in sufficient quantities has long been a topical area of agricultural production in Russia. The growth of grain production in modern conditions can be carried out mainly by increasing yields, which depends on agricultural technology, variety and quality of seed material [9]. One of the most important factors in the formation of high yields of good quality rice is balanced mineral nutrition for rice plants $[10,11]$. Rice varieties are sensitive to a deficiency of a particular nutrient, which leads to a decrease in productivity $[12,13]$. However, the influence of nitrogen fertilizers on culinary and nutritional qualities is ambiguous: an increased level of mineral nutrition leads to a decrease in vitreousity, an increase in fracturing, the number of underdeveloped grains, the stickiness of milled rice during cooking, and the time of the onset of maximum viscosity; higher doses of nitrogen during filling can lead to an increase in protein content and a decrease in amylose content $[14,15,16]$. Nitrogen nutrition affects both protein content and amylose content. The content of amylose at higher doses of nitrogen nutrition is much lower, while the content of protein is much higher. Such content of amylose when using high doses of nitrogen nutrition adversely affects the culinary and nutritional benefits of milled rice [17]. Nitrogen fertilizers have a positive effect on the yield of the head rice and the protein content [3], increase the transparency of brown (hulled) rice and the content of chalky grains [18]. According to other foreign sources, nitrogen fertilizers have a significant effect on all quality attributes, except for the gelatinization temperature, although in optimal doses nitrogen leads to an increase in the viscosity of the starch dispersion, but with a further increase in the dose of applied fertilizers, this indicator decreases [15]. The study of the effect of different seeding rates and doses of nitrogen fertilizers on fracturing and amylographic characteristics of starch dispersion in rice grain of Russian varieties is relevant in connection with the problem of nutritional value and improvement of their culinary merits.

\section{Materials and methods}

The aim of the study was to study the technological (fracturing) and amylographic characteristics of the grain starch dispersion of rice variety Rapan grown at different seeding rates and doses of nitrogen fertilizers.

The material of the research was the rice variety Rapan grown at experimental plot of the Federal Scientific Rice Centre at different seeding rates (4, 6, 8 million germinating seeds) and doses of nitrogen fertilizers $\left(\mathrm{N}_{0}, \mathrm{~N}_{92}, \mathrm{~N}_{138}\right.$ and $\left.\mathrm{N}_{184}\right)$ in 2018, 2019. Fracturing was determined using a DSZ-3 diaphanoscope, and the amylographic characteristics of a starch dispersion obtained from grain using a Brabender microviscoamylograph. The material for research was obtained from the laboratory of varietal agricultural technology and certification of rice varieties of the rice cultivation department.

\section{Results}

Within the framework of these studies, the most important physicochemical properties of the grain of the rice variety Rapan grown using various doses of nitrogen were determined. Below in Figures 1-3 the amylographic properties of the starch dispersion of grain are shown. 
Viscosity [BU]

Temperature $\left[{ }^{\circ} \mathrm{C}\right]$

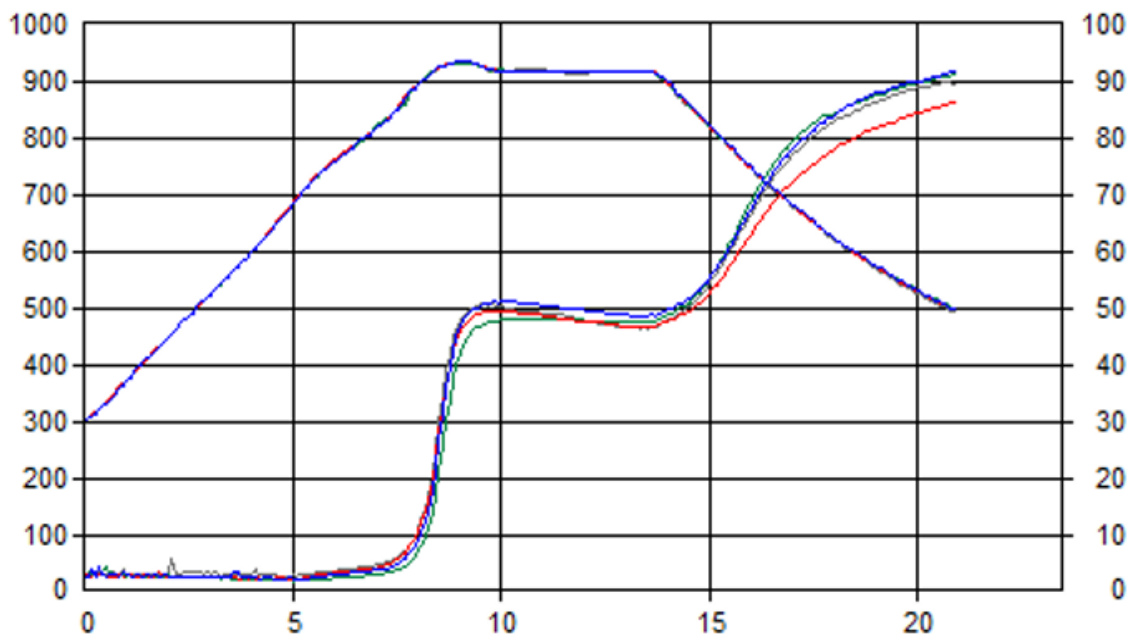

Time [min]

Rapan 4-0.vse

- Rapan 4-92 .vse

- Rapan 4-138 .vse

Rapan 4-184 .vse

Fig. 1. Graphs of the viscosity of the rice grain starch dispersion of variety Rapan at a seeding rate of 4 million germinating seeds using various doses of nitrogen, harvest 2018

The results were obtained on the assessment of fracturing, the most important technological grain quality trait, on which the milling yield and head rice content depend. The main amylographic parameters were determined: maximum viscosity and viscosity at the end of the cooling period. The data obtained are presented in tables 1-3.

Table 1. Physical and chemical properties of rice grain of the variety Rapan grown at a seeding rate of 4 million germinating seeds using various doses of nitrogen, harvest 2018-2019.

\begin{tabular}{|c|c|c|c|c|}
\hline $\begin{array}{c}\text { Nitrogen } \\
\text { dose, kg/ha } \\
\text { a.i. }\end{array}$ & Year & Fracturing, \% & $\begin{array}{c}\text { Maximum } \\
\text { viscosity, } \\
\text { Br. unit }\end{array}$ & $\begin{array}{c}\text { Viscosity at the end of } \\
\text { cooling period, } \\
\text { Br. unit }\end{array}$ \\
\hline \multirow{2}{*}{0} & 2018 & 23 & 508 & 862 \\
\cline { 2 - 5 } & 2019 & 8 & 540 & 708 \\
\hline \multirow{2}{*}{92} & 2018 & 31 & 484 & 873 \\
\cline { 2 - 5 } & 2019 & 13 & 471 & 611 \\
\hline \multirow{2}{*}{138} & 2018 & 25 & 497 & 816 \\
\cline { 2 - 5 } & 2019 & 10 & 473 & 613 \\
\cline { 2 - 5 } & 2018 & 20 & 512 & 877 \\
\hline
\end{tabular}

In 2018, a high value for "fracturing" was noted in the variety Rapan variety with a nitrogen dose of $92 \mathrm{~kg} / \mathrm{ha}$ of active ingredient, it was $31 \%$. At $\mathrm{N}_{184}$, the indicator of this trait decreased by $25 \%$. The maximum viscosity and viscosity at the end of cooling period increased with the same nitrogen doses by 28 and $4 \mathrm{Br}$. units respectively. In 2019, the indicators of the "fracturing" had lower values compared to the previous year: in the option without nitrogen - by $15 \%$, with $\mathrm{N}_{92}$ - by $18 \%$, with $\mathrm{N}_{138}$ - by $15 \%$, with $\mathrm{N}_{184}$ - by $14 \%$. The maximum viscosity and viscosity at the end of cooling period increased, depending on the increase in the nitrogen dose from 92 to $184 \mathrm{~kg} / \mathrm{ha}$ of active ingredient, and at the maximum nitrogen dose had parameters higher by 72 and $107 \mathrm{Br}$. units. 
The amylographic characteristics of the grain starch dispersion of rice variety Rapan grown at a seeding rate of 6 million viable seeds are shown in Figure 2.

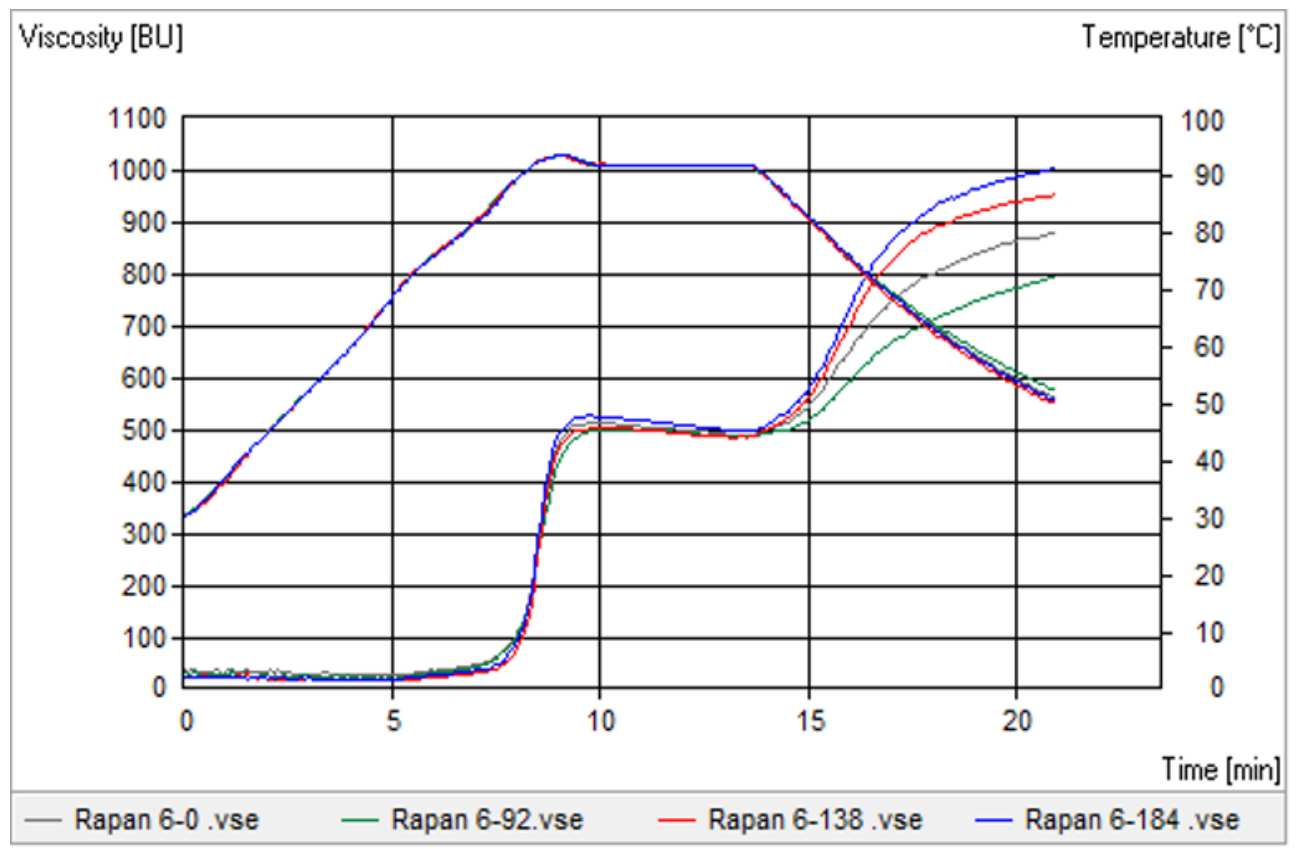

Fig. 2. Graphs of the viscosity of the rice grain starch dispersion of variety Rapan at a seeding rate of 6 million germinating seeds using various doses of nitrogen, harvest 2018

While the amylographic characteristics were relatively similar by the trait "maximum viscosity", significant differences were observed by "viscosity at the end of cooling period".

Table 2. Physical and chemical properties of rice grain of the variety Rapan grown at a seeding rate of 6 million germinating seeds using various doses of nitrogen, harvest 2018-2019.

\begin{tabular}{|c|c|c|c|c|}
\hline $\begin{array}{c}\text { Nitrogen } \\
\text { dose, kg/ha } \\
\text { a.i. }\end{array}$ & Year & Fracturing, \% & $\begin{array}{c}\text { Maximum } \\
\text { viscosity, } \\
\text { Br. unit }\end{array}$ & $\begin{array}{c}\text { Viscosity at the end of } \\
\text { cooling period, } \\
\text { Br. unit }\end{array}$ \\
\hline \multirow{2}{*}{0} & 2018 & 30 & 517 & 834 \\
\cline { 2 - 5 } & 2019 & 11 & 511 & 684 \\
\hline \multirow{2}{*}{92} & 2018 & 35 & 500 & 744 \\
\cline { 2 - 5 } & 2019 & 12 & 440 & 561 \\
\hline \multirow{2}{*}{138} & 2018 & 30 & 505 & 917 \\
\cline { 2 - 5 } & 2019 & 11 & 472 & 621 \\
\hline \multirow{2}{*}{184} & 2018 & 24 & 529 & 962 \\
\cline { 2 - 5 } & 2019 & 6 & 520 & 711 \\
\hline
\end{tabular}

In 2018, a high value for the "fracturing" was noted in the variety Rapan with a nitrogen dose of $92 \mathrm{~kg} /$ ha of active ingredient, it was 35\%. At $\mathrm{N}_{184}$, the indicator of this trait decreased by $11 \%$. The maximum viscosity and viscosity at the end of cooling period increased at the same nitrogen doses by 29 and $218 \mathrm{Br}$. units respectively. In 2019, the indicators for fracturing were lower than in the previous year: at $\mathrm{N}_{0}$ - by $19 \%$, at $\mathrm{N}_{92}$ - by $23 \%$, at $\mathrm{N}_{138}$ - by $19 \%$, at $\mathrm{N}_{184}$ - by $18 \%$. The maximum viscosity and viscosity at the end of cooling period increased, depending on the increase in the nitrogen dose from 92 to 184 
$\mathrm{kg} /$ ha of active ingredient, and at the maximum nitrogen dose they had parameters higher by 80 and $150 \mathrm{Br}$. units.

The amylographic characteristics of the grain starch dispersion of rice variety Rapan grown at a seeding rate of 8 million viable seeds are shown in Figure 3.

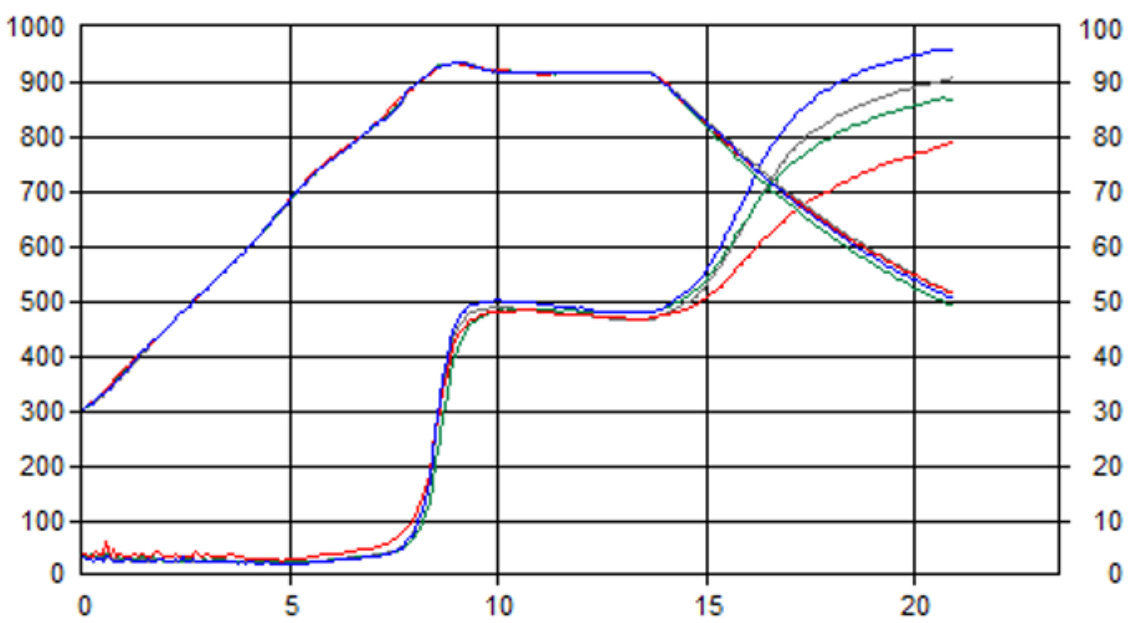

Time [min]

Rapan 8-0 .vse

- Rapan 8-92 .vse

- Rapan 8-138.vse

Rapan 8-184 .vse

Fig. 3. Graphs of the viscosity of the rice grain starch dispersion of variety Rapan at a seeding rate of 8 million germinating seeds using various doses of nitrogen, harvest 2018

The maximum viscosity at the highest seeding rate dropped slightly, and the viscosity at the end of cooling period had a wide range of values.

Table 3. Physical and chemical properties of rice grain of the variety Rapan grown at a seeding rate of 8 million germinating seeds using various doses of nitrogen, harvest 2018-2019.

\begin{tabular}{|c|c|c|c|c|}
\hline $\begin{array}{c}\text { Nitrogen } \\
\text { dose, kg/ha } \\
\text { a.i. }\end{array}$ & Year & Fracturing, \% & $\begin{array}{c}\text { Maximum } \\
\text { viscosity, } \\
\text { Br. unit }\end{array}$ & $\begin{array}{c}\text { Viscosity at the end of } \\
\text { cooling period, } \\
\text { Br. unit }\end{array}$ \\
\hline \multirow{2}{*}{0} & 2018 & 29 & 490 & 864 \\
\cline { 2 - 5 } & 2019 & 8 & 512 & 680 \\
\hline \multirow{2}{*}{92} & 2018 & 41 & 485 & 831 \\
\cline { 2 - 5 } & 2019 & 12 & 480 & 636 \\
\hline \multirow{2}{*}{138} & 2018 & 35 & 487 & 739 \\
\cline { 2 - 5 } & 2019 & 10 & 492 & 651 \\
\hline \multirow{2}{*}{184} & 2018 & 18 & 504 & 925 \\
\cline { 2 - 5 } & 2019 & 5 & 563 & 748 \\
\hline
\end{tabular}

At a seeding rate of 8 million germinating seeds in 2018, by the trait "fracturing", as in the variants with a seeding rate of 4 and 6 million germinating seeds, there was a high value in variety Rapan at a nitrogen dose of $92 \mathrm{~kg} /$ ha of the active ingredient amounted to $41 \%$. At $\mathrm{N}_{184}$, the indicator of this trait decreased by $23 \%$. The maximum viscosity and viscosity at the end of cooling period increased with the same nitrogen doses by 19 and $94 \mathrm{Br}$. units respectively. In 2019, the indicators for "fracturing” were lower than in the previous year: 
at $\mathrm{N}_{0}$ - by $21 \%$, at $\mathrm{N}_{92}$ - by $29 \%$, at $\mathrm{N}_{138}$ - by $25 \%$, at $\mathrm{N}_{184}$ - by $13 \%$. The maximum viscosity and viscosity at the end of cooling period increased, depending on the increase in the nitrogen dose from 92 to $184 \mathrm{~kg}$ / ha of active ingredient, and at the maximum nitrogen dose had parameters higher by 83 and $112 \mathrm{Br}$. units.

\section{Discussion}

When developing new rice varieties, breeders are guided not only by the yield, but also by the grain quality of the varieties obtained, since this makes it possible to have highly productive varieties in production, and for processors to select unique rice materials for the food industry. The culinary preferences of the population, as a rule, determine such characteristics of rice grain quality as the broken rice content, the temperature of gelatinization of the starch dispersion, the consistency of glued starch [19, 20, 21].

The literature contains data on the influence on the nutritional and culinary advantages of rice not only by the genotype, but also by the growing conditions [22]. Planting density and the use of nitrogen fertilizers are important agronomic factors affecting rice growth, yield and grain quality.

Nitrogen fertilizers have a positive effect on the yield of whole grain and the protein content in milled rice [3]. In the experiments of Mandana Tayefe with the use of various doses of nitrogen fertilizers, a significant difference was noted in all quality traits, except for the gelatinization temperature, and the highest amylose content was observed in the control variant (without fertilizers) [15]. Chinese scientist Sun Tao confirmed the effect of nitrogen nutrition on starch content and fine structure, enzymatic activity and expression of genes associated with starch synthesis, which leads to changes in rice viscosity and taste [6]. The highest maximum viscosity was observed when plants were treated with nitrogen fertilizers with a dose of nitrogen $\mathrm{N}_{60}$; with an increase in the dose, the indicators of the gel consistency also increased [15]. The introduction of increased doses of nitrogen fertilizers increases the stickiness of milled rice during cooking, the time of the onset of maximum viscosity, which corresponds to the results we obtained in the study [23, 24, 25]. The study showed that with an increase in nitrogen doses (from 92 to $184 \mathrm{~kg} /$ ha of active ingredient), there is a decrease in fracturing and an increase in the viscosity parameters of starch dispersion, which is consistent with the results $[6,15]$.

\section{Conclusions}

When cultivating the variety Rapan at different seeding rates and using nitrogen doses of 0 , 92, 138 and $184 \mathrm{~kg} /$ ha of active ingredient, a tendency was observed in the change of quality traits. In the samples grown without the use of nitrogen, low fracturing was noted, which reached maximum values at $\mathrm{N}_{92}$ and $\mathrm{N}_{138}$, at $\mathrm{N}_{184}$, this trait had minimum values. On the contrary, viscosity indices were maximum at the minimum values of fracturing and decreased at high values of this trait.

This work was supported by the Russian Foundation for Basic Research and the Ministry of Education, Science and Youth Policy of Krasnodar region. Grant No. 19-416-233013 r_mol_a 


\section{References}

1. M.A. Fitzgerald Rice: characteristics and quality requirements, Cereal Grains, Assessing and Managing Quality, $212 \quad$ - 236, (2010), https://doi.Org/10.1533/9781845699529.2.212

2. N.G. Tumanyan, S.S. Chizhikova, K.K. Olkhovaya, Culinary characteristics and nutritional advantages of rice varieties of Federal Scientific Rice Centre, Rice growing, 2 (47), 29-36, (2020)

3. F.L. Checchio Mingotte, R.K. Hanashiro, D.F. Filho, Physico-chemical parameters of rice cultivars fertilized with nitrogen, Semina: Ciencias Agrarias, 33, 2605-2618, (2012), DOI:10.5433/1679-0359.2012v33Supl1p2605

4. Z. A. Syahariza, S. Sar, J. Hasjim, M. J. Tizzotti, R. G. Gilbert, Food Chem, 136(2), 742 - 749, (2013), doi: 10.1016/j.foodchem.2012.08.053

5. J.S. Bao, Rice, Eating quality, Food Science, 166-175, (2015), https://doi.org/10.1016/B978-0-08-100596-5.00133-5

6. S. Tao, T. Laga, Zh. Shuyu, W. Haiwei, H. Yunfei, Zh. Zhongchen, J. Zhengxun, Effects of nitrogen fertilizer application on starch quality, activities and gene expression levels of related enzymes in rice endosperm, Chinese Journal of Rice Science (CJRS), 32(5), 475-484, (2018), doi: 10.16819/j.1001-7216.2018.8013

7. D.M. Garcia, P.Z. Bassinello, D.R. Palmirez Ascheri, J.L. Ramirez Ascheri, J.B. Trovo, R. Cobucci, Cooking quality of upland and lowland rice characterized by different methods, Food Science and Technology, 31(2), 341-348, (2011), DOI 10.1590/S010120612011000200010

8. Y. Yang, G. Lin, X. Yu, Y. Wu, Rice starch accumulation at different endosperm regions and physical properties under nitrogen treatment at panicle initiation stage, International Journal of Biological Macromolecules, 160, 328-339, (2020), DOI:10.1016/j.ijbiomac.2020.05.210

9. E.Yu. Papulova, T.B. Kumeiko, N.G. Tumanyan, Yu.V. Tkachenko, A.S. Karamov, Variability of grain amylographic characteristics of rice varieties grown with different doses of nitrogen fertilizer, Rice growing, 2 (47), 37-43, (2020)

10. K. Saito, E. Vandamme, J. Johnson, A. Tanaka, Yield-limiting macronutrients for rice in sub-Saharan Africa, Geoderma, 338, (2018)

11. Y. Song, I.Y. Choi, P.K. Sharma, Ch.H. Kang, Effect of Different Nitrogen Doses on the Storage Proteins and Palatability of Rice Grains of Primary and Secondary Rachis Branches, Plant Production Science, 15(4), 253-257, (2012), doi 10.1626/pps.15.253

12. H.K. Park, M.G. Choi, T.S. Park, B.I. Ku, Y.D. Kim, J.K. Ko, W.Y. Choi and B.K. Kim, Effect of low nitrogen fertilizer application on growth, yield and quality of rice, Kor. J. Int. Agri, 21, 252-260, (2009)

13. H. Yoshida, K. Takehisa, T. Kojima, H. Ohno, K. Sasaki, H. Nakagawa, Modeling the effects of $\mathrm{N}$ application on growth, yield and plant properties associated with the occurrence of chalky grains of rice, Plant Production Science, 19(1), 30-42, (2016), DOI:10.1080/1343943X.2015.1128111

14. J.I. Kim, H.C. Choi, K.H. Kim, J.K. Ahn, N.B. Park, D.S. Park, C.S. Kim, J.Y. Lee and J.K. Kim, Varietal response to grain quality and palatability of cooked rice influenced by different nitrogen applications, Kor. J. Crop Sci, 54, 13-23, (2009)

15. M. Tayefe, A. Gerayzade, E. Amiri and A.N. Zade, Effect of nitrogen on rice yield, yield components and quality parameters, African Journal of Biotechnology, 13(1), 91105, (2014), DOI: 10.5897/AJB11.2298, ISSN 1684-5315 
16. Y. Pang, J. Ali, X. Wang, N.J. Franje, J.E. Revilleza, J. Xu, Zh. Li, Relationship of Rice Grain Amylose, Gelatinization Temperature and Pasting Properties for Breeding Better Eating and Cooking Quality of Rice Varieties, Plos One, (2016), https://doi.org/10.1371/journal.pone.0168483.

17. M. Martin, M. A. Fitzgerald, Proteins in rice grains influence cooking properties, J. Cereal Sci., 36, 285-294 (2002)

18. C.M. Perez, B.O. Juliano, S.K. De Datta, S.T. Amarante, Effects of nitrogenfertilizer treatment and source and season on grain quality of IR64 rice, Plant Food Hum. Nutr., 40, 123-130 (1990)

19. N.G. Tumanyan, Rice is more than a commodity, Rice growing, 13, 77 (2009)

20. E.M. Kharitonov, N.G. Tumanyan, Problems of rice growing in the Russian Federation and ways to solve them. Rice quality. Achievements of science and technology of the agro-industrial complex, 11, 14-15 (2010)

21. R.P.R. Cuevas, V.O. Pede, J. McKinley, Or. Velarde, M. Demont, Grain Quality and Consumer Preferences: A Case Study of Two Rural Towns in the Philippines, Plos ONE (2016), https://doi.org/10.1371/journal.pone.0150345

22. J. Gu, Jing Chen, L. Chen, Zh. Wang, H. Zhang, J. Yang, Grain quality changes and responses to nitrogen fertilizer of japonica rice cultivars released in the Yangtze River Basin from the 1950s to 2000s, The Crop Journal, 3(4), 285-297 (2015), https://doi.Org/10.1016/j.cj.2015.03.007

23. K. Amritpal, Gh. Atinder, S. Narpinder, K. Seeratpreet [et al] Effect of different doses of nitrogen on protein profiling, pasting and quality attributes of rice from different cultivars, Journal of Food Science and Technology, 53, 2452 - 2462 (2016)

24. X. M. Cao, H. Y. Sun, C. G. Wang [et al], Effects of late-stage nitrogen fertilizer application on the starch structure and cooking quality of rice, J. Sci. Food Agric., 98, 2332 - 2340 (2017)

25. Zh. Chanchan, Yu. Huangl, B. Jia, Ya. Wang [at al], Effects of Cultivar, Nitrogen Rate, and Planting Density on Rice-Grain Quality, Agronomy, 8(11), 246 (2018), https://doi.Org/10.3390/agronomy8110246 